\title{
Study of Cross-Linking between Boric Acid and Different Types of Polyvinyl Alcohol Adhesive
}

\author{
Ravindra V. Gadhave*, Prakash A. Mahanwar, Pradeep T. Gadekar \\ Department of Polymer and Surface Engineering, Institute of Chemical Technology, Mumbai, India \\ Email: ^ravi.gadhave3@gmail.com
}

How to cite this paper: Gadhave, R.V., Mahanwar, P.A. and Gadekar, P.T. (2019) Study of Cross-Linking between Boric Acid and Different Types of Polyvinyl Alcohol Adhesive. Open Journal of Polymer Chemistry, 9, 16-26.

https://doi.org/10.4236/ojpchem.2019.9100

Received: January 2, 2019

Accepted: February 16, 2019

Published: February 19, 2019

Copyright $\odot 2019$ by author(s) and Scientific Research Publishing Inc. This work is licensed under the Creative Commons Attribution International License (CC BY 4.0).

http://creativecommons.org/licenses/by/4.0/

\begin{abstract}
Polyvinyl alcohol (PVA) is water-soluble polymer manufactured by the saponification of polyvinyl acetate. The physical properties and its specific application depend on the degree of hydrolysis. To enhance the properties of different hydrolyzed PVA grades, it is generally chemically modified with various cross-linkers. Here, different degree hydrolyzed PVA grades with enhanced properties were achieved by cross-linking with boric acid. These samples were then characterized by Differential Scanning Calorimetry (DSC) and Gel permeation chromatography (GPC). For further analysis a film of samples were prepared by casting on glass plate. The effects of amount of boric acid and degree of hydrolysis of PVA on performance properties like tensile strength, pencil hardness and thermal properties like glass transition temperature were studied. The results showed that by cross-linking there was an increase in mechanical strength and thermal property.
\end{abstract}

\section{Keywords}

Polyvinyl Alcohol, Boric Acid, Degree of Hydrolysis, Wood Adhesive

\section{Introduction}

Polyvinyl alcohol (PVA) is one of the most important commercial water soluble polymers. It possesses high crystalline structure [1]-[6]. Through the years PVA has been used for various applications. It has very low cost and has been used for wood binding [7] [8]. Due to its highly polar hydroxyl group, it also absorbs water readily, thereby joining the family of water soluble polymers. Its water solubility property plays an important role in making it compatible with various types of polymers [9] [10]. The PVA adhesive cures by evaporating water and forming a high strength $\mathrm{H}$-bonding. PVA is synthetic polymer with excellent film-forming property, emulsifying properties and outstanding resistance to oil, 
grease, and solvents [11]. It has excellent gas barrier properties, high strength, and flexibility. However, it presents some drawbacks, like the high melting point $\left(220^{\circ} \mathrm{C}-245^{\circ} \mathrm{C}\right)$ when compared to other conventional polymers, so it is necessary to reduce the melting point or to protect the PVA from decomposition [12] [13].

PVA is made by dissolving another polymer, polyvinyl acetate (PVAc), in an alcohol such as methanol, and treating it with an alkaline catalyst such as sodium hydroxide. The resulting hydrolysis reaction removes the acetate groups from the PVAc molecules without disrupting their long-chain structure. Based on the degree of hydrolysis, PVA is classified into grades of partially (85\% $89 \%)$ and fully (97\% - 99\%) hydrolyzed polymers [14].

Cross-linking is a common approach to improve the performance of PVA for various applications. PVA has been cross-linked with cross-linking agents, such as weak Lewis acid aluminium chloride, zirconium chloride, titanium chloride, etc. The cross-linking helps to improve the mechanical properties and water stability of PVA based products. Boric acid is a commonly used cross-linker for PVA for various applications. Similarly, the boric acid forms strong bonds with hydroxyl groups due to presence of vacant d-orbital in boron, which causes it to rapidly react with various nucleophiles to form complexes. Since the PVA and starch are rich in hydroxyl groups, boric acid can be expected to cross-link with them and further improve the adhesion [15].

In this study, different hydrolyzed PVA is cross-linked in water solution with boric acid as a cross-linking agent to observe the effects on physical, mechanical and thermal properties of PVA solutions.

\section{Experimental}

\section{1) Materials}

Partially hydrolyzed PVA-PH PVA (Degree of hydrolysis (DOH) of $88 \%$ to $89 \%$ ), fully hydrolyzed PVA-FH PVA (DOH of $97 \%$ to $99 \%$ ) and Modified PVA-M PVA (DOH of $97 \%$ to $99 \%$ ) obtained from Kuraray Co., Ltd., India. These raw materials were kept in dry environment to avoid absorption of moisture. Boric acid used for the study was obtained from Sigma-Aldrich.

\section{2) Preparation method}

PVA solution was made by taking water and PVA grade (different DOH) as shown in Table 1 . The given amount of boric acid was added to the solution at $50^{\circ} \mathrm{C}$, and then the temperature was raised to $92^{\circ} \mathrm{C}-95^{\circ} \mathrm{C}$ and kept for about 2.5 hours with continuous stirring with overhead stirrer. Then the solution was cool down to $25^{\circ} \mathrm{C}$, to get the PVA adhesive.

3) Film casting method

\section{Characterization and Testing}

\section{1) Brookfield viscosity}

Viscosities were measured using Brookfield DV1 Viscometer. 
Table 1. Composition of the ingredients for the preparation of PVA adhesive.

\begin{tabular}{|c|c|c|c|c|c|}
\hline Sr. No & $\begin{array}{c}\text { PH PVA } \\
\text { (DOH } 88 \% \text { to } \\
89 \%)\end{array}$ & $\begin{array}{c}\text { FH PVA } \\
\text { (DOH 97\% to } \\
99 \%)\end{array}$ & $\begin{array}{c}\text { M PVA } \\
\text { (DOH 97\% to } \\
99 \%)\end{array}$ & Boric acid & Water \\
\hline 1 & 18 & - & - & 0 & 82 \\
\hline 2 & 18 & - & - & 0.5 & 82 \\
\hline 3 & 18 & - & - & 1.0 & 82 \\
\hline 4 & 18 & - & - & 1.5 & 82 \\
\hline 5 & - & 18 & - & 0 & 82 \\
\hline 6 & - & 18 & - & 0.5 & 82 \\
\hline 7 & - & 18 & - & 1.0 & 82 \\
\hline 8 & - & 18 & - & 1.5 & 82 \\
\hline 9 & - & - & 18 & 0 & 82 \\
\hline 10 & - & - & 18 & 0.5 & 82 \\
\hline 11 & - & - & 18 & 1.0 & 82 \\
\hline 12 & - & - & 18 & 1.5 & 82 \\
\hline
\end{tabular}

\section{2) Differential scanning calorimetry (DSC)}

Glass transition temperature $\left(T_{g}\right)$ of casted films was evaluated by Perkin Elmer DSC using TA instrument Q100 DSC.

3) Gel permeation chromatography (GPC)

The GPC spectrums were acquired using a high pressure chromatography system. The GPC column temperature was maintained at $25^{\circ} \mathrm{C}$. The carrier medium used was tetrahydrofuran (THF).

4) Pencil hardness test

Each prepared solution was casted into film on clear glass plate using a bar coater 1000 microns. The casted film was cured for 24 hours at ambient conditions. Pencil hardness was tested as per ASTM D 3363 testing method to test the pencil hardness of the casted film.

5) Ultimate stress of films

Each prepared solution was casted into film on clear glass plate using a bar coater 1000 microns. The casted film was cured for 24 hours at ambient conditions. Ultimate stress and ultimate strain of films were determined by using UTM Tinus Olsen 5ST.

\section{6) Tensile strength}

Tensile strength was checked on wooden strips and tested with the help of UTM Tinus Olsen H25KT. A uniform thin layer of adhesive was applied on to $25 \mathrm{~mm} \times 25 \mathrm{~mm}$ area of one end of the canarium wood pieces. The adhesive coated canarium wood pieces were assembled in such a way that the grains of two pieces were oriented in parallel. Each end of the sample was tightly held together in a vice and kept for $4 \mathrm{hrs}, 6 \mathrm{hrs}$ and $24 \mathrm{hrs}$ at ambient conditions and pulled apart at a controlled rate of $5 \mathrm{~mm} / \mathrm{min}$ and tensile strength for adhesive bond was recorded. 


\section{Results and Discussion}

\section{1) $\operatorname{Viscosity}(R T)$}

The crosslinking reaction between PVA with Cross-linker 1 caused an increase in the viscosity of solution as shown in Table 2.

The boric acid reacts with the PVA and forms the cross-link. The cross-links make it harder for chains to move, which causes the increase in viscosity. The PH PVA has higher viscosity than FH PVA due to more entanglement in PH PVA, since the PH PVA less order and orientation which causes the chains to entangle between them. The M PVA has the lowest viscosity due to very less H-bonding, caused due to modification of PVA (shown in Figure 1).

\section{2) Glass transition temperature $\left(T_{g}\right)$}

There is an increase in $T_{g}$ after cross-linking it with boric acid as seen from Table 3.

The cross-linking mechanism has led to coming together of chains. Due to close proximity between chains the intermolecular interactions increase and lead to increase in $T_{g}$. The FH PVA shows the highest $T_{g}$ due to high crystallinity as compared to PH PVA and M PVA. The crystallinity causes greater orientation as well as H-bonding. The M PVA has the least $T_{g}$ due to very less H-bonding as compared to PH PVA and FH PVA (shown in Figure 2). These all combined effect lead to greater $T_{g}$ in FH PVA.

\section{3) Molecular weight}

The crosslinking mechanism has caused an increase in molecular weight of all the PVA as shown in Table 4.

The cross-linking of PVA has led to increase in molecular weight; the chains which initially were smaller have become larger due to cross-linking. The number of repeating units in the chain has significantly increased due to cross-linking.

Table 2. Viscosity data for PVA adhesive cross-linked with boric acid.

\begin{tabular}{cccc}
\hline \multirow{2}{*}{$\begin{array}{c}\text { Concentration of } \\
\text { boric acid (\%) }\end{array}$} & PH PVA & FH PVA & M PVA \\
\cline { 2 - 4 } 0 & 271 & 226 & 3 \\
0.5 & 300 & 322 & 4 \\
1 & 472 & 358 & 4 \\
1.5 & 600 & 568 & 4 \\
\hline
\end{tabular}

Table 3. $T_{g}$ data for PVA adhesive cross-linked with boric acid.

\begin{tabular}{cccc}
\hline \multirow{2}{*}{$\begin{array}{c}\text { Concentration of } \\
\text { boric acid (\%) }\end{array}$} & \multicolumn{3}{c}{ Glass transition temperature $\left({ }^{\circ} \mathrm{C}\right)$} \\
\cline { 2 - 4 } 0 & PH PVA & FH PVA & M PVA \\
\hline 0.5 & 72 & 79 & 76 \\
1 & 72 & 80 & 79 \\
1.5 & 75 & 81 & 78 \\
\hline
\end{tabular}


Table 4. Molecular weight data for PVA adhesive crosslinked with boric acid.

\begin{tabular}{cccc}
\hline \multirow{2}{*}{$\begin{array}{c}\text { Concentration of } \\
\text { boric acid (\%) }\end{array}$} & PH PVA & FH PVA & M PVA \\
\cline { 2 - 4 } & 99,030 & 94,478 & 31,662 \\
$\mathbf{0}$ & 104,492 & 94,924 & 32,430 \\
$\mathbf{1}$ & 104,688 & 95,174 & 32,840 \\
1.5 & 105,732 & 95,561 & 32,605 \\
\hline
\end{tabular}

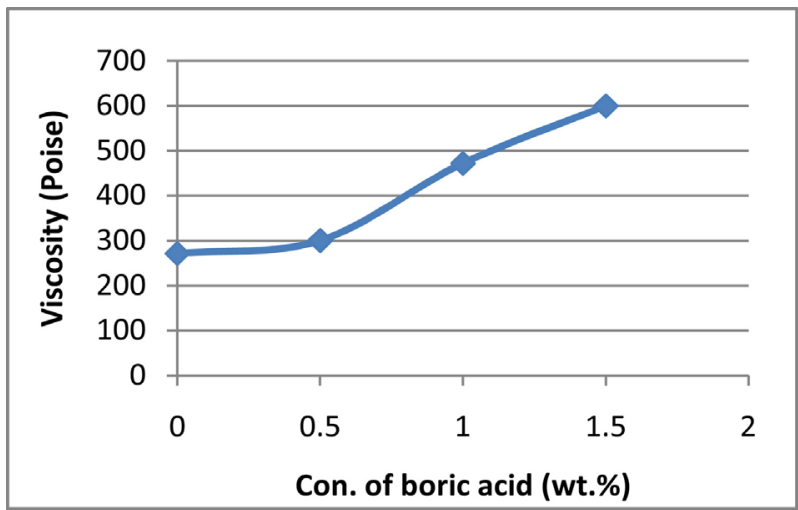

(a)

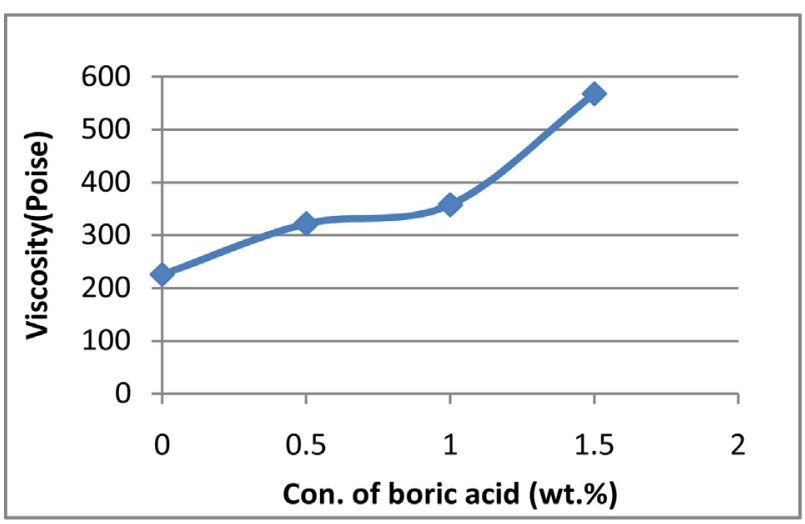

(b)

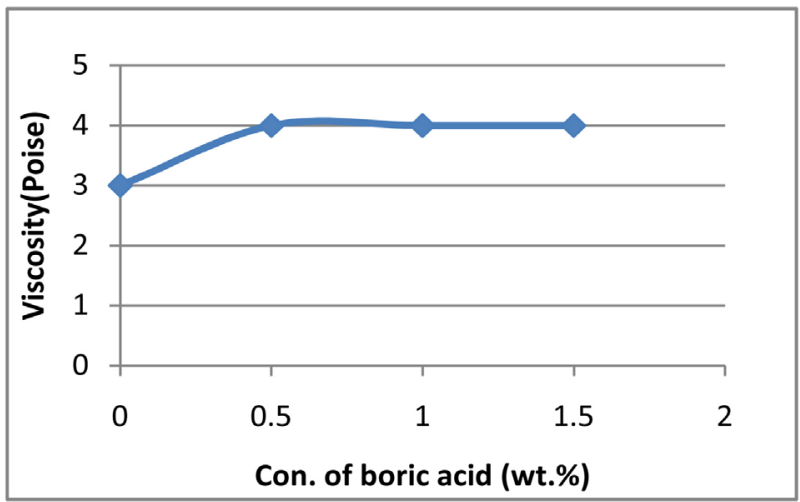

(c)

Figure 1. Illustration showing the viscosity vs concentration of boric acid (wt. \%) profiles of (a) PH PVA (Standard deviation $(\sigma) 154.23)$, (b) FH PVA $(\sigma 144.2)$ and (c) M PVA $(\sigma 0.5)$. 


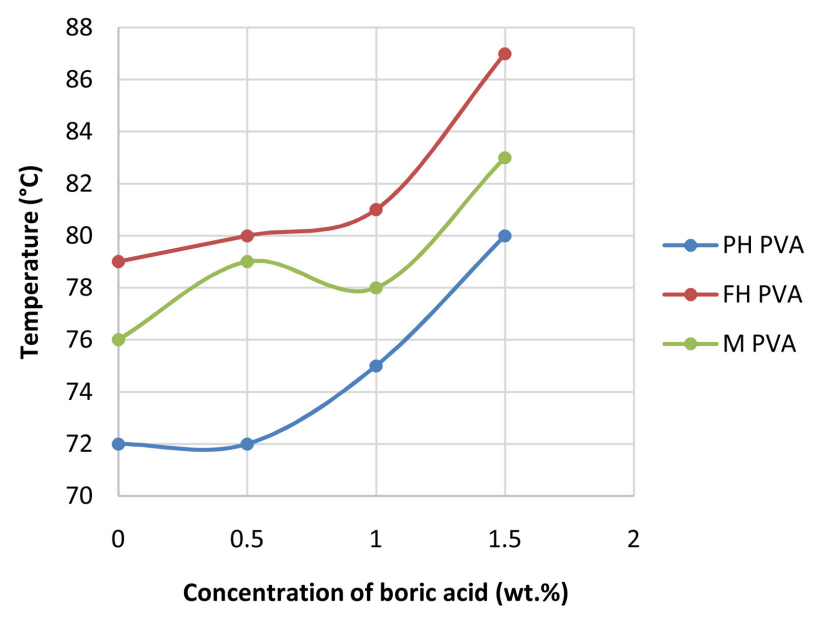

Figure 2. Illustration of glass transition temperature in $\mathrm{PH}$ PVA $(\sigma 3.775)$, FH PVA ( $\sigma 3.594)$ and M PVA $(\sigma 2.944)$.

Additionally, the cross-linking establishes multi-dimensional 3-D structure. This increase in chain length leads to increase in molecular weight in all the grades of PVA (shown in Figures 3(a)-(c)).

Although while comparing the increase of PH PVA with FH PVA, it is seen that the PH PVA has the greater molecular weight as compared to FH PVA, this can be attributed to the better cross-linking in PH PVA, as the chains are not that tightly spaced the boric acid can easily attack the hydroxyl groups of $\mathrm{PH}$ PVA. This has led to better cross-linking of PH PVA as compared to FH PVA.

4) Pencil hardness

The pencil hardness increases as amount of boricacid in the PVA solutions increases as shown in Table 5.

The main factor influencing the hardness of the films is the presence of long chains. The longer chains of PVA in the backbone increase the hardness of the cross-linked PVA, since this makes them stiff and hard for penetration. The crystallinity in FH PVA is greater due to high degree of hydrolysis as compared to PH PVA and M PVA, this has led to increase in hardness. As a result, it becomes increasingly difficult to put dent onto the surface of the PVA adhesive (shown in Table 5).

5) Ultimate force

The ultimate force required to break the film has increased as the concentration of boric acid increases as shown in Table 6 .

The films prepared show an increase in ultimate force, this is mainly due to better cohesion between chains for PVA cross-linked with boric acid. Since, the chains are in closer proximity in case of FH PVA as compared to PH PVA and M PVA, with introduction of boric acid the spacing between chains has decreased with is responsible for better cohesion and in turn better ultimate force while braking of film (shown in Figure 4).

6) Tensile shear strength

Due to increase in boric acid there is an increase in tensile strength of PVA 


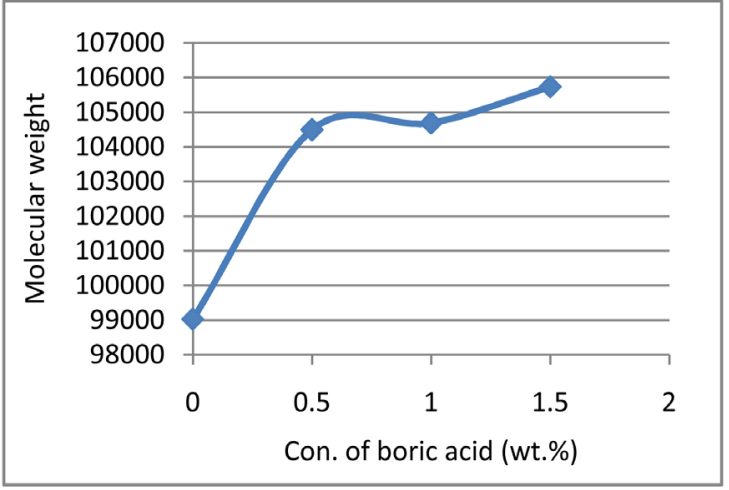

(a)

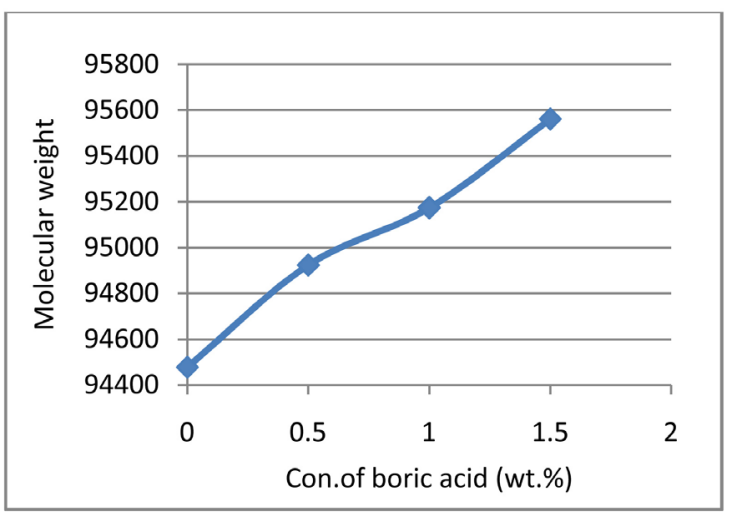

(b)

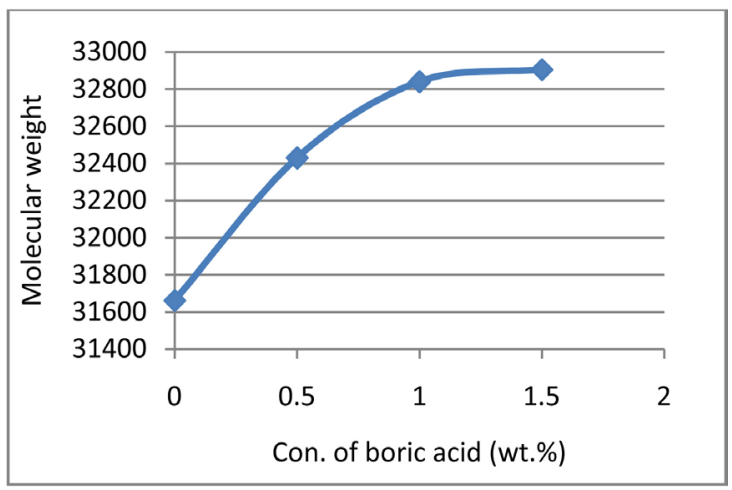

(c)

Figure 3. Illustration of molecular weight vs concentration of boric acid (wt.\%) profiles of (a) PH PVA, (b) FH PVA and (c) M PVA.

adhesive as shown in Table 7.

The cross-linking reaction between PH PVA and boric acid caused an increase in the tensile strength of the glue (shown in Figure 5(a)). The same trend was observed when FH PVA and M PVA were cross-linked with boric acid (shown in Figure 5(b) and Figure 5(c)). The viscosity and tensile strength are directly proportional to each other. With increase in viscosity, the inter-molecular forces are increased which contribute to the tensile strength development. The bringing together of chains has caused a greater cohesion in the adhesive upon which; the 


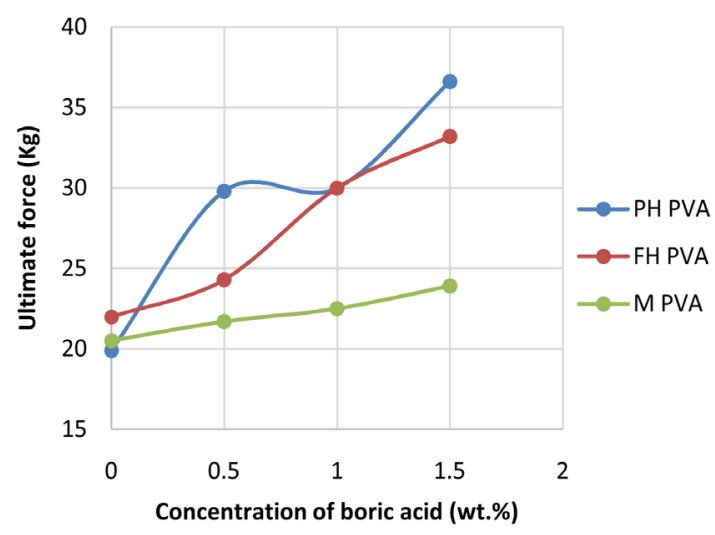

Figure 4. Illustration of viscosity vs. concentration of boric acid (wt.\%) profiles of (a) PH PVA, (b) FH PVA and (c) M PVA.

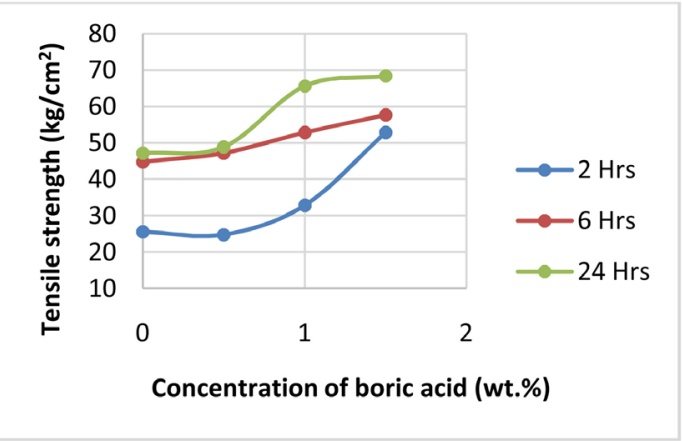

(a)

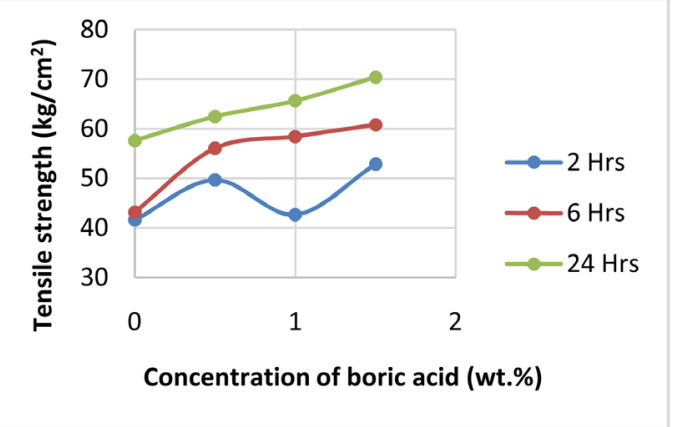

(b)

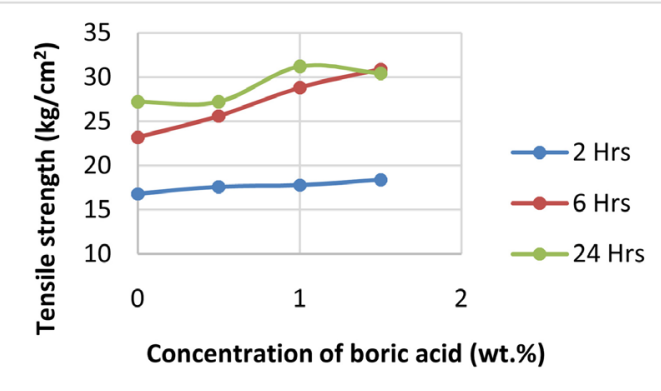

(c)

Figure 5. Illustration showing the tensile strength vs the concentration of boric acid (wt.\%) profiles of (a) PH PVA, (b) FH PVA and (c) M PVA. 
Table 5. Pencil hardness data for PVA adhesive cross-linked with boric acid.

\begin{tabular}{cccc}
\hline \multirow{2}{*}{$\begin{array}{c}\text { Concentration of } \\
\text { boric acid (\%) }\end{array}$} & \multicolumn{3}{c}{ Pencil hardness (HB) } \\
\cline { 2 - 4 } & PH PVA & FH PVA & M PVA \\
\hline 0 & $1 \mathrm{H}$ & $3 \mathrm{H}$ & $2 \mathrm{H}$ \\
0.5 & $3 \mathrm{H}$ & $3 \mathrm{H}$ & $3 \mathrm{H}$ \\
1 & $4 \mathrm{H}$ & $4 \mathrm{H}$ & $4 \mathrm{H}$ \\
1.5 & $5 \mathrm{H}$ & $4 \mathrm{H}$ & $5 \mathrm{H}$ \\
\hline
\end{tabular}

Table 6. Ultimate force data for PVA adhesive cross-linked with boric acid.

\begin{tabular}{cccc}
\hline \multirow{2}{*}{$\begin{array}{c}\text { Concentration of } \\
\text { boric acid (\%) }\end{array}$} & PH PVA & Ultimate force (kg) \\
\cline { 2 - 4 } & 19.9 & FH PVA & M PVA \\
\hline 0 & 29.8 & 22 & 20.5 \\
0.5 & 30 & 24.3 & 21.7 \\
1 & 36.6 & 30 & 22.5 \\
1.5 & & 33.2 & 23.9 \\
\hline
\end{tabular}

Table 7. Tensile strength data for PH PVA, FH PVA and M PVA adhesive cross-linked with boric acid.

\begin{tabular}{|c|c|c|c|c|}
\hline \multirow{2}{*}{ PVA } & \multirow{2}{*}{$\begin{array}{l}\text { Concentration of } \\
\text { boric acid (wt.\%) }\end{array}$} & \multicolumn{3}{|c|}{ Tensile strength $\left(\mathrm{kg} / \mathrm{cm}^{2}\right)$} \\
\hline & & $2 \mathrm{Hrs}$ & $6 \mathrm{Hrs}$ & $24 \mathrm{Hrs}$ \\
\hline \multirow{4}{*}{ PH PVA } & 0 & 25.6 & 44.8 & 47.2 \\
\hline & 0.5 & 24.8 & 47.2 & 48.8 \\
\hline & 1 & 32.8 & 52.8 & 65.6 \\
\hline & 1.5 & 52.8 & 57.6 & 68.4 \\
\hline \multirow{4}{*}{ FH PVA } & 0 & 41.6 & 43.2 & 57.6 \\
\hline & 0.5 & 49.6 & 56 & 62.4 \\
\hline & 1 & 42.6 & 58.4 & 65.6 \\
\hline & 1.5 & 52.8 & 60.8 & 70.4 \\
\hline \multirow{4}{*}{ M PVA } & 0 & 16.8 & 23.2 & 27.2 \\
\hline & 0.5 & 17.6 & 25.6 & 27.2 \\
\hline & 1 & 17.8 & 28.8 & 31.2 \\
\hline & 1.5 & 18.4 & 30.9 & 30.4 \\
\hline
\end{tabular}

force required to separate this cohesion is high. The greater this force, higher will be its tensile strength value (shown in Table 7).

The FH PVA has the greatest tensile strength compared to PH PVA and $\mathrm{M}$ PVA, since the FH PVA has the better orientation and crystallinity it has the highest tensile strength. Consequently, the M PVA has the least orientation which yields the least crystallinity which has caused the lesser tensile strength in them. 


\section{Conclusion}

The enhancement of properties has been observed with increasing content of boric acid. The boric acid acts as the cross-linker for PVA. With addition of boric acid, it was observed that the properties such as viscosity, tensile strength, pencil hardness, molecular weight, ultimate strength and glass transition temperature all increased. The FH PVA shows the maximum increase in properties due to better cross-linking in them. The boric acid can easily access the hydroxyl groups of PVA, as compared to PH PVA. The highest tensile strength values are of FH PVA due to H-bonding and highly cross-linked structure. The M PVA shows the least improvement in properties due to lower molecular weight and ethylene modification. This will help to formulate water based adhesive.

\section{Conflicts of Interest}

The authors declare no conflicts of interest regarding the publication of this paper.

\section{References}

[1] Othman, N., Azahari, N.A. and Ismail, H. (2011) Thermal Properties of Polyvinyl Alcohol (PVOH)/Corn Starch Blend Film. Malaysian Polymer Journal, 6, 147-154.

[2] Gadhave, R.V., Kasbe, P.S., Mahanwar, P.A. and Gadekar, P.T. (2018) To Study the Effect of Boric Acid Modification on Starch-Polyvinyl Alcohol Blend Wood Adhesive. Journal of the Indian Academy of Wood Science, 15, 190-198 https://doi.org/10.1007/s13196-018-0225-2

[3] Stauffer, S.R. and Peppas, N.A. (1992) Poly(vinyl alcohol) Hydrogels Prepared by Freezing-Thawing Cyclic Processing. Polymer, 33, 3932.

[4] Gadhave, R.V., Mahanwar, P.A. and Gadekar, P.T. (2018) Starch Stabilized Polyvinyl Acetate Emulsion: Review. Polymers from Renewable Resources, 9, 75-84.

[5] Nambu, M. (1984) Freeze-Dried Poly(vinyl alcohol) Gel. US Patent No. 4472542.

[6] Othman, N., Azahari, N.A. and Ismail, H. (2011) Thermal Properties of Polyvinyl Alcohol (PVOH)/Corn Starch Blend Film. Malaysian Polymer Journal, 6, 147-154.

[7] Gu, R., Mu, B. and Guo, K. (2013) Structural Characterization of Konjak Powder-Chitosan-PVA Blending Adhesive. Nongye Gongcheng Xuebao/Transactions of the Chinese Society of Agricultural Engineering, 29, 277-283.

[8] Prosanov, I.Y., Abdulrahman, S.T., Thomas, S., Bulina, N.V. and Gerasimov, K.B. (2018) Complex of Polyvinyl Alcohol with Boric Acid: Structure and Use. Materials Today Communications, 14, 77-81. https://doi.org/10.1016/j.mtcomm.2017.12.012

[9] Wu, Z.J., Wu, J.J., Peng, T.T., Li, Y.T., Lin, D., Xing, B., Li, C., Yang, Y., Yang, L., Zhang, L., Ma, R., Wu, W., Lv, X., Dai, J. and Han, G. (2017) Preparation and Application of Starch/Polyvinyl Alcohol/Citric Acid Ternary Blend Antimicrobial Functional Food Packaging Films. Polymers, 9, 102.

[10] Sanjiv Kasbe, P., Kumar, N. and Manik, G. (2017) A Molecular Simulation Analysis of Influence of Lignosulphonate Addition on Properties of Modified 2-Ethyl Hexyl Acrylate/Methyl Methacrylate/Acrylic Acid Based Pressure Sensitive Adhesive. International Journal of Adhesion and Adhesives, 78, 45-54. https://doi.org/10.1016/j.ijadhadh.2017.06.014

[11] Chana, J., Forbes, B. and Jones, S.A. (2008) The Synthesis of High Molecular 
Weight Partially Hydrolysed Poly(vinyl alcohol) Grades Suitable for Nanoparticle Fabrication. Journal of Nanoscience and Nanotechnology, 8, 5739-5747.

[12] Priya, B., Gupta, V.K., Pathania, D. and Singha, A.S. (2014) Synthesis, Characterization and Antibacterial Activity of Biodegradable Starch/PVA Composite Films Reinforced with Cellulosic Fibre. Carbohydrate Polymers, 109, 171-179.

[13] Wang, N., Zhao, L.P., Zhang, C.H. and Li, L. (2016) Water States and Thermal Processability of Boric Acid Modified Poly(vinyl alcohol). Journal of Applied Polymer Science, 133, Article ID: 43246. https://doi.org/10.1002/app.43246

[14] Sharma, V.K., Yngard, R.A. and Lin, Y. (2009) Silver Nanoparticles: Green Synthesis and Their Antimicrobial Activities. Advances in Colloid and Interface Science, 145, 83-96.

[15] Yin, Y., Li, J., Liu, Y. and Li, Z. (2005) Starch Cross-Linked with Poly(vinyl alcohol) by Boric Acid. Journal of Applied Polymer Science, 96, 1394-1397. 